\title{
Knowledge regarding lifestyle and cardiovascular risk factors in rural community
}

\author{
Priti Lata Mondal ${ }^{1,}{ }^{*}$, Jayanta Sadhu ${ }^{2}$, Abdul Karim ${ }^{3}$ and Beauty Begum ${ }^{4}$ \\ ${ }^{1}$ National Institute of Diseases of the Chest and Hospital, Dhaka, Bangladesh. \\ ${ }^{2}$ Bangladesh University of Engineering and Technology (BUET), Dhaka, Bangladesh. \\ ${ }^{3}$ College of Nursing, Sher-E-Bangla Nagar, Dhaka, Bangladesh. \\ ${ }^{4}$ Kurmitola General Hospital, Dhaka Cantonment, Dhaka-1206, Bangladesh.
}

International Journal of Biological and Pharmaceutical Sciences Archive, 2021, 02(01), 062-071

Publication history: Received on 17 June 2021; revised on 30 July 2021; accepted on 02 August 2021

Article DOI: https://doi.org/10.53771/ijbpsa.2021.2.1.0064

\begin{abstract}
Cardiovascular Disease (CVD) is one of the leading causes of death worldwide, making it a major public health problem in Bangladesh also. A descriptive cross-sectional study was carried out in Joykhali village, Batiaghata upazilla in Khulna district from January to December 2019 to assess the level of knowledge regarding lifestyle and cardiovascular risk factors in rural community. A total of 288 people were selected from each house by conveniently. Data were collected by using pre tested semi-structured questionnaire with face-to-face interview. Out of the 288 respondents, 43 (14.9\%) had good knowledge while others had average $(n=211,73.3 \%)$ and poor $(n=34,11.8 \%)$ knowledge regarding risk factors of cardiovascular disease. Only 25 (8.7\%) respondents had good knowledge while others had average ( $\mathrm{n}=190$, $66.0 \%)$ and poor $(n=73,25.3 \%)$ knowledge regarding sign and symptoms of cardiovascular disease. Majority of the respondents $(61.1 \%)$ had good knowledge while others had average $(n=105,36.5 \%)$ and poor $(n=7,2.4 \%)$ knowledge regarding prevention of cardiovascular disease. There is an apparent need to establish more wide-spread and effective educational intervention, which should be sensitive to the abilities of targeted individuals.
\end{abstract}

Keywords: Cerebrovascular disease; Life style; Dietary pattern; Modifiable risk factors; Stress

\section{Introduction}

Cardiovascular Disease (CVD) is one of the leading causes of death worldwide, making it a major public health problem. It is the number one cause of morbidity and mortality worldwide [1].

According to the World Health Organization, 17.9 million people died from cardiovascular diseases in 2016 which represents $31 \%$ of all global deaths. This number is expected to grow to $2.3 \%$ of total population [2]. Unhealthy lifestyle habits are a major contributor to cardiovascular disease. The situation gets even worse in third world country like Bangladesh. About $80 \%$ of the deaths from cardiovascular disease occur in low income third world countries. Most of the time, the cause of such diseases is unhealthy lifestyle pattern and ignorance about the risk factors of cardiovascular disease. The rising prevalence of CVD in these Low- and Middle-Income Countries (LMICs) is driven by rapid urbanization and its corollary of westernization of lifestyles [3].

Knowledge about Cardiovascular disease and its modifiable risk factors is a vital pre-requisite to change the individuals' health attitudes, behaviors and lifestyle practices. Knowledge improvement to the recognition of heart attack and stroke symptoms will lead to earlier presentation to medical care that may result in better outcomes. Good knowledge about cardiovascular disease risk factors to be proactive in decreasing majority risk factors is modifiable [4].

\footnotetext{
${ }^{*}$ Corresponding author: Priti Lata Mondal

National Institute of Diseases of the Chest and Hospital, Dhaka, Bangladesh. Email-ashees2020@gmail.com 
Cardiovascular disease is the commonest form of heart disease and the single most important cause of premature death in the developed and developing countries. With the improvement of socio-economic status, urbanization and changes of dietary habits and lifestyle, the incidence of ischemic heart disease is also increasing in the developing countries, including Bangladesh. So, a cardiovascular disease is becoming a serious public health problem in Bangladesh. Prevalence of cardiovascular disease in Bangladesh is 20-25\% [5].

Modification of risk factors is an effective way to reduce cardiovascular disease risk. Most Cardiovascular risk factors can be altered with lifestyle changes and medications. The causes of cardiovascular disease largely rely on high blood pressure, LDL cholesterol, lifestyle pattern including physical activity, smoking alcohol consumption, body mass index (BMI) and dietary factors [6]. The increasing rates in developing and recently developed populations mirror historic epidemiologic data in high income nations. The causes of this global epidemic have largely been established to originate in high blood pressure, LDL cholesterol, lifestyle factors including physical activity, smoking, alcohol consumption, body mass index (BMI) and dietary factors direct impact of established and novel pathways of clinical cardiovascular risk [7].

Cardiovascular disease is a metabolic disease. It has no specific organism or agent, only some risk factors which is modifiable by changing of lifestyle like stop using of tobacco regular physical exercise like walking, cycling, swimming, avoid use of excessive sugar and edible salt, talking balanced diet, stop use of alcohol, less use of edible oil and intake of animal fat, avoid stress and sedentary habits, control of diabetes, hyper tension and body weight. Smoking is difficult habit to break. In fact, only 4 to 7 percent of individuals successfully quit on their own, without any kind of aid or reinforcement. But several options can significantly increase chances of quitting; these include nicotine replacement therapy, medication and counseling. With counseling plus nicotine replacement or medication, this number rises to 25 to 33 percent. Nicotine replacement therapy minimizes symptoms of nicotine withdrawal and helps control cravings [8].

The lifestyle choices make have a significant impact on risk of CVD and ability to manage the disease once it develops. In addition, it will need to adopt a heart-healthy lifestyle. Lifestyle changes can help make more effective and the results more long lasting. There are four components to a healthy lifestyle, like-diet, exercise, sleep, and thought. So, there are recommended lifestyle measures for the prevention and treatment of cardiovascular disease. Many studies have examined the relationship overall dietary patterns and the risks of CVD, HF and stroke. Diet is a key modifiable risk factor in the prevention and risk reduction of cardiovascular disease. To plan and execute preventing strategy for cardiovascular disease detailed information on the disease, its causes and cure play an effective and vital role. [7]. Finding of this study is expected to identify the Knowledge Regarding Lifestyle and Cardiovascular Risk Factors in Rural Community. More over this study will help health care providers to develop or strengthen their ability to protect their clients and the surrounding community from cardiovascular diseases.

\section{Material and methods}

\subsection{Study design}

The study design was a descriptive type of cross-sectional study.

\subsection{Study population \& Sample}

Study population was rural people of Joykhali, Batiaghata upazilla, at Khulna, sample population was selected conveniently from the selected upazilla.

\subsection{Study place}

The study was carried out in Joykhali village, Batiaghata upazilla in Khulna district.

\subsection{Study period}

The study was conducted for the one year during the period of $1^{\text {st }}$ January to $31^{\text {st }}$ December 2019.

\subsection{Sample size}

The sampling size was determined by the following formula. Sample size for that proposed study was calculated by the following formula- 


$$
n=\frac{z^{2} p q}{d^{2}}
$$

Where,

$\mathrm{n}=$ required sample size

$\mathrm{z}=$ standard normal distributaries with $95 \%$ confidential level 1.96

$\mathrm{p}=$ proportion of dependent variable $=40 \% .14=0.40$

$\mathrm{q}=1-\mathrm{p}=1-0.40=0.6$

$\mathrm{d}=$ decision or proportion of error \%; usually set as $5 \%=0.05$

$$
\text { So, } \mathrm{n}=\frac{(1.96)^{2} \times(0.25) \times(0.75)}{(0.05)^{2}}
$$

$=288.12$

With rounding the value population size was 288 .

\subsection{Inclusion Criteria}

- Rural community people aged between $18-80$ years

- Willing to participate and give inform written consent

- Physically and mentally be able to answer complete questionnaire

- Permanent resident in the selected area

\subsection{Exclusion Criteria}

- Medical history of CVD

- Mentally disable person

- Seriously ill patients

\subsection{Sampling Technique}

Convenience sampling was adopted. Each house in the village was selected and one person was selected from each house.

\subsection{Data Collection tools}

A pre-tested modified self-administered semi structured questionnaire was used to collect the data.

\subsection{Data collection technique}

By face-to-face interview.

\subsection{Data management and analysis plan}

After completion of data collection, the data were checked and edited manually and verified before tabulation. Data were coded, entered and analyzed in a computer. The statistical analysis was conducted using SPSS (Statistical Package for Social Science) version 26 statistical software for windows. The findings of the study were presented by frequency, percentage in tables and graphs. Means and standard deviation for continuous variables and frequency distribution for categorical variables were used to describe the characteristics of the total sample. Age, number of family members was considered as categorical variables. Relationships of the categorical data were assessed using Chi-square test and Fisher's exact test. Here, $\mathrm{p}<0.05$ was considered significant and all $\mathrm{p}$-values were two sided.

\section{Results}

This cross-sectional study was carried out among 288 rural community people to assess the level of knowledge regarding life style and cardio-vascular risk factors. Data were collected with a pre-tested questionnaire. This chapter presents findings of those data. 
Table 1 Socio-demographic status of the respondents

\begin{tabular}{|c|c|c|}
\hline Age (in years) & Frequency (n) & Percent (\%) \\
\hline $18-27$ & 50 & 17.4 \\
\hline $28-37$ & 73 & 25.3 \\
\hline $38-47$ & 75 & 26.0 \\
\hline $48-57$ & 61 & 21.2 \\
\hline$>58$ & 29 & 10.1 \\
\hline \multicolumn{3}{|l|}{ Mean \pm SD $40.53 \pm 13.23$} \\
\hline \multicolumn{3}{|l|}{ Sex } \\
\hline Female & 188 & 65.3 \\
\hline Male & 100 & 34.7 \\
\hline \multicolumn{3}{|l|}{ Educational status } \\
\hline Illiterate & 61 & 21.2 \\
\hline Primary & 73 & 25.3 \\
\hline Secondary & 101 & 35.1 \\
\hline HSC and above & 53 & 18.4 \\
\hline \multicolumn{3}{|l|}{ Occupational status } \\
\hline House wife & 145 & 50.3 \\
\hline $\begin{array}{l}\text { Service holder (government and } \\
\text { nongovernment) }\end{array}$ & 43 & 14.9 \\
\hline Farmer and day labourer & 42 & 14.6 \\
\hline Businessman & 30 & 10.4 \\
\hline Student & 14 & 4.9 \\
\hline Others (jobless, transport workers) & 14 & 4.9 \\
\hline \multicolumn{3}{|l|}{ Marital status } \\
\hline Married & 262 & 91.0 \\
\hline Unmarried & 19 & 6.6 \\
\hline Widow & 7 & 2.4 \\
\hline \multicolumn{3}{|l|}{ Type of family } \\
\hline Nuclear & 145 & 50.3 \\
\hline Joint & 143 & 49.7 \\
\hline \multicolumn{3}{|l|}{ Monthly family income (in taka) } \\
\hline Up to 10000 & 21 & 7.3 \\
\hline $10001-15000$ & 131 & 45.5 \\
\hline $15001-20000$ & 71 & 24.7 \\
\hline $20001-25000$ & 32 & 11.1 \\
\hline$>25000$ & 33 & 11.5 \\
\hline
\end{tabular}


Table 1 shows that $50(17.4 \%)$ respondents belonged to $18-27$ years age group, $73(25.3 \%)$ respondents belonged to 28-37 years age group, 75 (26.0\%) respondents belonged to 38-47 years age group, 61 (21.2\%) respondents belonged to $48-57$ years age group and $29(10.1 \%)$ respondents belonged to $>58$ years age group. The mean age of the respondents was $40.53( \pm 13.23)$ years which ranged from $18-78$ years. Among the 288 respondents, $188(65.3 \%)$ were female and rests $(n=100,34.7 \%)$ were male. From them, $61(21.2 \%)$ respondents were illiterate while 73 (25.3\%) respondents had educational status up to primary, 101 (35.1\%) respondents had educational status up to secondary and $53(18.4 \%)$ respondents had educational status up to HSC and above. Here, 145 (50.3\%) respondents were house wives while 43 (14.9\%) were service holders, 42 (14.6\%) were farmer and day labourer, $30(10.4 \%)$ were businessman, $14(4.9 \%)$ were students and 14 (4.9\%) were involved in other professions and $262(91.0 \%)$ respondents were married, $19(6.6 \%)$ were unmarried and few $(n=7,2.4 \%)$ were widows. From them, 145 (50.3\%) respondents belonged to nuclear family while 143 (49.7\%) respondents belonged to joint family. Out of total respondents, 131 (45.5\%) respondents had monthly family income from 10001 to 15000 taka, 71 (24.7\%) respondents had monthly family income from 15001-20000 taka, 32 (11.1\%) respondents had monthly family income from 20001-25000 taka, and 33 (11.5\%) respondents had monthly family income from $>25000$ taka.

Table 2 Distribution of respondents by knowledge regarding risk factors of cardiovascular diseases $(n=288)$

\begin{tabular}{|c|c|c|c|}
\hline Variables & $\begin{array}{l}\text { Agree } \\
\text { f (\%) }\end{array}$ & $\begin{array}{l}\text { Don't know } \\
\text { f (\%) }\end{array}$ & $\begin{array}{l}\text { Disagree } \\
\text { f (\%) }\end{array}$ \\
\hline High blood pressure is a risk factor for cardiovascular disease & $282(97.7)$ & $5(1.7)$ & $1(0.3)$ \\
\hline Blood pressure of $120 / 80 \mathrm{mmHg}$ is considered as normal range & $23(7.9)$ & $265(92.1)$ & $0(0.0)$ \\
\hline Diabetes mellitus is a risk factor for developing heart diseases & $67(23.3)$ & $221(76.7)$ & $0(0.0)$ \\
\hline High cholesterol is a risk factor for heart disease & $162(56.3)$ & $124(41.1)$ & $2(0.7)$ \\
\hline Stress is a risk factor for heart disease & $157(54.5)$ & $106(36.8)$ & $25(8.7)$ \\
\hline $\begin{array}{l}\text { Being overweight increases a person's risk for coronary heart } \\
\text { disease }\end{array}$ & $265(92.0)$ & $19(6.6)$ & $4(1.4)$ \\
\hline $\begin{array}{l}\text { Physical inactivity is an important risk factor for developing heart } \\
\text { disease }\end{array}$ & $72(25.0)$ & $216(75.0)$ & $0(0.0)$ \\
\hline $\begin{array}{l}\text { Smoking tobacco increases the chances of developing heart } \\
\text { diseases }\end{array}$ & $286(99.3)$ & $2(0.7)$ & $0(0.0)$ \\
\hline $\begin{array}{l}\text { Abdominal obesity (fat belly) is a risk factor for developing heart } \\
\text { diseases }\end{array}$ & $160(55.6)$ & $108(37.5)$ & $20(6.9)$ \\
\hline Older people are at a greater risk for developing heart disease & $210(72.9)$ & $62(21.5)$ & $16(5.6)$ \\
\hline Genetic factor is a risk factor for developing heart disease & $7(2.3)$ & $254(88.2)$ & $27(9.5)$ \\
\hline Familial history is a risk factor for developing heart disease & $228(79.2)$ & $59(21.5)$ & $1(0.3)$ \\
\hline Adding table salt to diet increases risk of heart disease & $287(99.7)$ & $1(0.3)$ & $0(0.0)$ \\
\hline Man has a higher risk of heart disease than woman & $93(32.3)$ & $105(36.4)$ & $90(31.2)$ \\
\hline Eating an unhealthy diet is a significant risk factor for heart disease & $268(93.1)$ & $17(5.9)$ & $3(1.0)$ \\
\hline
\end{tabular}

Table 2 shows that, most of the respondents (92.0\% -99.7\%) knew that high blood pressure, being overweight, smoking tobacco, adding table salt to diet and eating an unhealthy diet were significant risk factor for heart disease. Majority of the respondents (55.6\%-79.2\%) knew that high cholesterol, abdominal obesity (fat belly), family history and old age are risk factors for developing heart disease. Majority of the respondents (51.0\%-76\%) did not know that diabetes mellitus, physical inactivity is risk factor for developing heart diseases and man have a higher risk of heart disease than woman.

Figure 1 shows that, 43 (14.9\%) respondents had good knowledge while others had average (n=211, 73.3\%) and poor $(\mathrm{n}=34,11.8 \%)$ knowledge regarding risk factors of cardiovascular disease. 


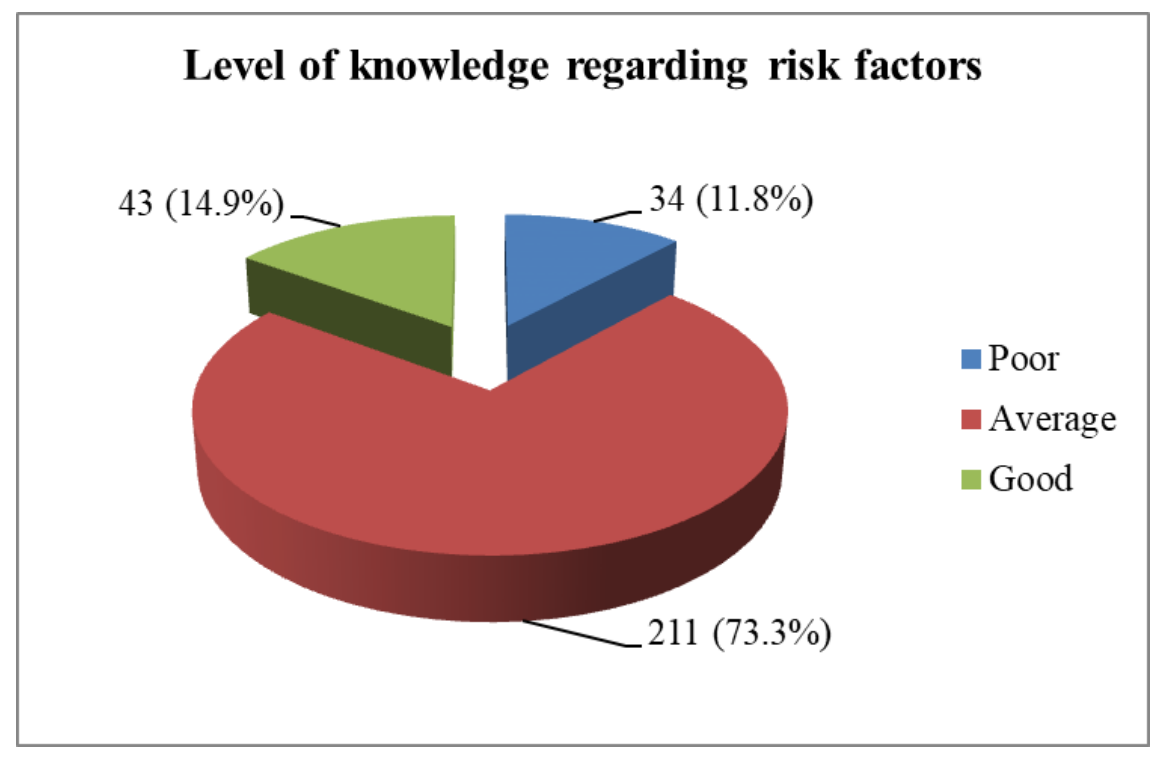

Figure 1 Distribution of respondents by level of knowledge regarding risk factors $(\mathrm{n}=288)$

Table 3 Distribution of respondents by knowledge regarding sign and symptoms of cardiovascular diseases (n=288)

\begin{tabular}{|c|c|c|c|}
\hline Variables & $\begin{array}{l}\text { Agree } \\
\text { f (\%) }\end{array}$ & $\begin{array}{l}\text { Don't know } \\
\text { f (\%) }\end{array}$ & $\begin{array}{l}\text { Disagree } \\
\text { f (\%) }\end{array}$ \\
\hline Pain in chest is a symptoms of heart disease & $286(99.3)$ & $2(0.7)$ & $0(0.0)$ \\
\hline $\begin{array}{l}\text { Pain in shoulder, and arms or discomfort in the neck and back are } \\
\text { symptoms of heart disease }\end{array}$ & $222(77.1)$ & $8(2.8)$ & $0(0.0)$ \\
\hline Nausea and vomiting are signs of heart attack & $54(18.8)$ & $225(78.1)$ & $9(3.1)$ \\
\hline Shortness of breath are signs of heart attack & $160(55.6)$ & $128(44.4)$ & $0(0.0)$ \\
\hline Heart burn and sweating are signs of heart attack & $34(11.8)$ & $240(83.3)$ & $14(4.9)$ \\
\hline Palpitation, dizziness and fainting are sign of heart attack & $46(16.0)$ & $240(83.3)$ & $2(0.7)$ \\
\hline $\begin{array}{l}\text { Sudden trouble seeing in one or both eyes is a symptom of heart } \\
\text { attack }\end{array}$ & $153(53.1)$ & $126(43.8)$ & $9(3.1)$ \\
\hline
\end{tabular}

Table 3 shows that, most of the respondents $(n=286,99.3 \%)$ knew that pain in is a symptom of heart disease. Majority of the respondents $(n=222,77.1 \%)$ knew that pain in shoulder, and arms or discomfort in the neck and back are symptoms of heart disease. Majority of the respondents $(81.2 \%-88.2 \%)$ did not know that nausea and vomiting, palpitation, dizziness and fainting and heart burn and sweating are signs of heart attack.

Figure 2 shows that, only 25 (8.7\%) respondents had good knowledge while others had average (n=190, 66.0\%) and poor $(n=73,25.3 \%)$ knowledge regarding sign and symptoms of cardiovascular disease.

Table 4 shows that, most of the respondents (88.2\% -99.7\%) knew that one should control high blood pressure, control over weight, avoid alcohol consumption, stops smoking, reduce stress and maintaining a balanced lifestyle to lower risk of developing coronary heart disease. However, 228 (79.2\%) respondents did not know that regular physical activities will lower a person's chance of getting heart disease and 263 (91.3\%) respondents did not know that one should control high blood sugar to prevent heart disease.

Figure 3 shows that, $176(61.1 \%)$ respondents had good knowledge while others had average $(n=105,36.5 \%)$ and poor $(n=7,2.4 \%)$ knowledge regarding prevention of cardiovascular disease. 


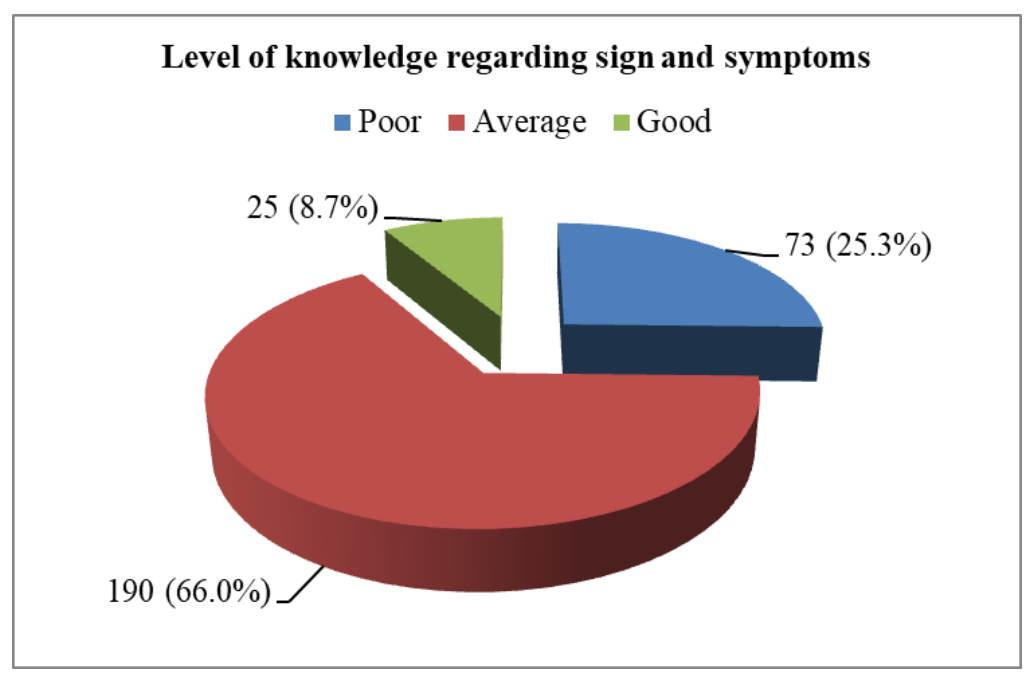

Figure 2 Distribution of respondents by level of knowledge regarding sign and symptoms of cardiovascular diseases $(n=288)$

Table 4 Distribution of respondents by knowledge regarding prevention of cardiovascular diseases $(n=288)$

\begin{tabular}{|c|c|c|c|}
\hline Variables & $\begin{array}{l}\text { Agree } \\
\text { f (\%) }\end{array}$ & $\begin{array}{l}\text { Don't know } \\
\quad \text { f }(\%)\end{array}$ & $\begin{array}{l}\text { Disagree } \\
\text { f (\%) }\end{array}$ \\
\hline It is essential to control high blood pressure to prevent heart disease & $287(99.7)$ & $1(0.3)$ & $0(0.0)$ \\
\hline $\begin{array}{l}\text { Regular physical activities will lower a person's chance of getting } \\
\text { heart disease }\end{array}$ & $60(20.8)$ & $228(79.2)$ & $0(0.0)$ \\
\hline Control LDL cholesterol to prevent heart disease & $162(56.3)$ & 106 (36.) & $20(6.9)$ \\
\hline Control high blood sugar to prevent heart disease & $25(8.7)$ & $200(69.4)$ & $63(21.9)$ \\
\hline $\begin{array}{l}\text { Controlling over weight will lower a person's chance of getting heart } \\
\text { disease }\end{array}$ & $255(88.5)$ & $32(11.1)$ & $1(0.3)$ \\
\hline Avoid alcohol consumption to reduce chance of heart disease & $280(97.2)$ & $8(2.8)$ & $0(0.0)$ \\
\hline $\begin{array}{l}\text { A person who stops smoking will lower their risk of developing } \\
\text { coronary heart disease }\end{array}$ & $285(98.9)$ & $3(1.0)$ & $0(0.0)$ \\
\hline Reduce stress to prevent heart disease & $285(98.9)$ & $3(1.0)$ & $0(0.0)$ \\
\hline $\begin{array}{l}\text { Maintaining a balanced lifestyle is necessary to prevent heart } \\
\text { disease }\end{array}$ & 254 (88.2) & $34(11.8)$ & $0(0.0)$ \\
\hline
\end{tabular}

Table 5 shows that, all of the respondents $(n=288,100.0 \%)$ knew that eating red meat and too much salt increases high blood pressure. Most of the respondents (95.7\% -99.0\%) knew that regular intake of healthy diet, tobacco product consumption increases risk of heart disease and a person who stops alcohol consumption will lower the risk of developing coronary heart disease. Among the respondents, 189 (65.6\%) did not know that walking and gardening are considered types of physical activity to lower heart disease risk and 246 (85.4\%) did not know that leafy vegetables is good for controlling heart disease and maintaining good health.

Figure 4 shows that, 188 (65.3\%) respondents had good knowledge while others had average (n=100, 34.7\%) knowledge regarding life style pattern. 


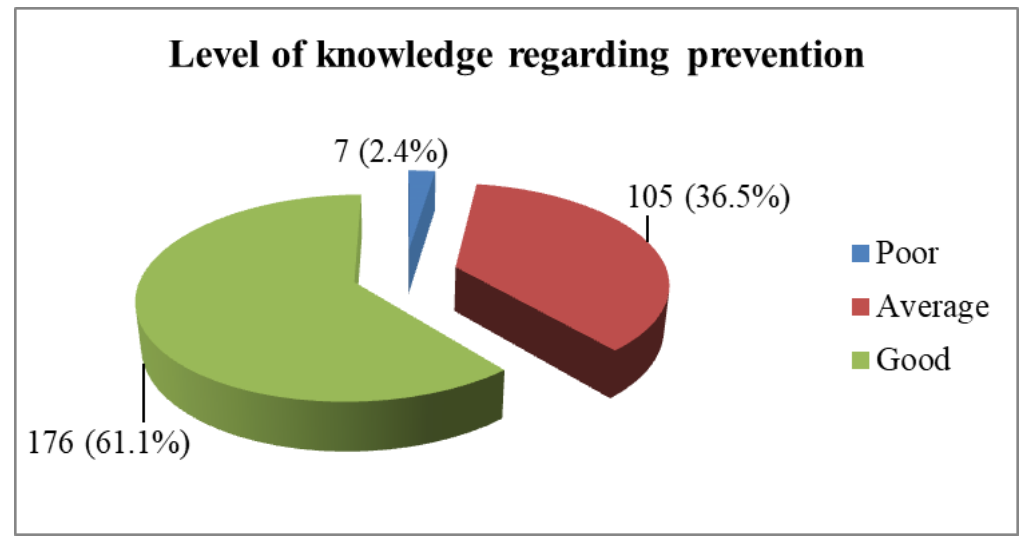

Figure 3 Distribution of respondents by level of knowledge regarding prevention of cardiovascular diseases ( $\mathrm{n}=288)$

Table 5 Distribution of respondents by knowledge regarding life style pattern $(n=288)$

\begin{tabular}{|l|c|c|c|}
\hline Variables & $\begin{array}{c}\text { Agree } \\
\mathbf{f ~ ( \% )}\end{array}$ & $\begin{array}{c}\text { Don't know } \\
\mathbf{f ~ ( \% )}\end{array}$ & $\begin{array}{c}\text { Disagree } \\
\mathbf{f ~ ( \% )}\end{array}$ \\
\hline $\begin{array}{l}\text { Regular intake of healthy diet is necessary to prevent heart } \\
\text { disease }\end{array}$ & $285(99)$ & $3(1.0)$ & $0(0.0)$ \\
\hline Eating red meat increases risk of developing heart disease & $288(100)$ & $0(0.0)$ & $0(0.0)$ \\
\hline $\begin{array}{l}\text { Walking and gardening are considered types of physical activity } \\
\text { to lower heart disease risk. }\end{array}$ & $99(34.4)$ & $180(62.5)$ & $9(3.1)$ \\
\hline $\begin{array}{l}\text { Leafy vegetables are good for controlling heart disease and } \\
\text { maintaining good health }\end{array}$ & $42(14.6)$ & $146(50.7)$ & $100(34.7)$ \\
\hline Regular 30 minutes walking is good for health & $201(69.8)$ & $87(30.2)$ & $0(0.0)$ \\
\hline Eating too much salt increases high blood pressure & $288(100)$ & $0(0.0)$ & $0(0.0)$ \\
\hline Tobacco product consumption increases risk of heart disease & $280(97.2)$ & $8(2.8)$ & $0(0.0)$ \\
\hline $\begin{array}{l}\text { A person who stops alcohol consumption will lower the risk of } \\
\text { developing coronary heart disease }\end{array}$ & $275(95.5)$ & $13(4.5)$ & $0(0.0)$ \\
\hline Getting enough quality sleep [6-8hour/day] is good for health & $210(72.9)$ & $70(24.3)$ & $8(2.8)$ \\
\hline
\end{tabular}

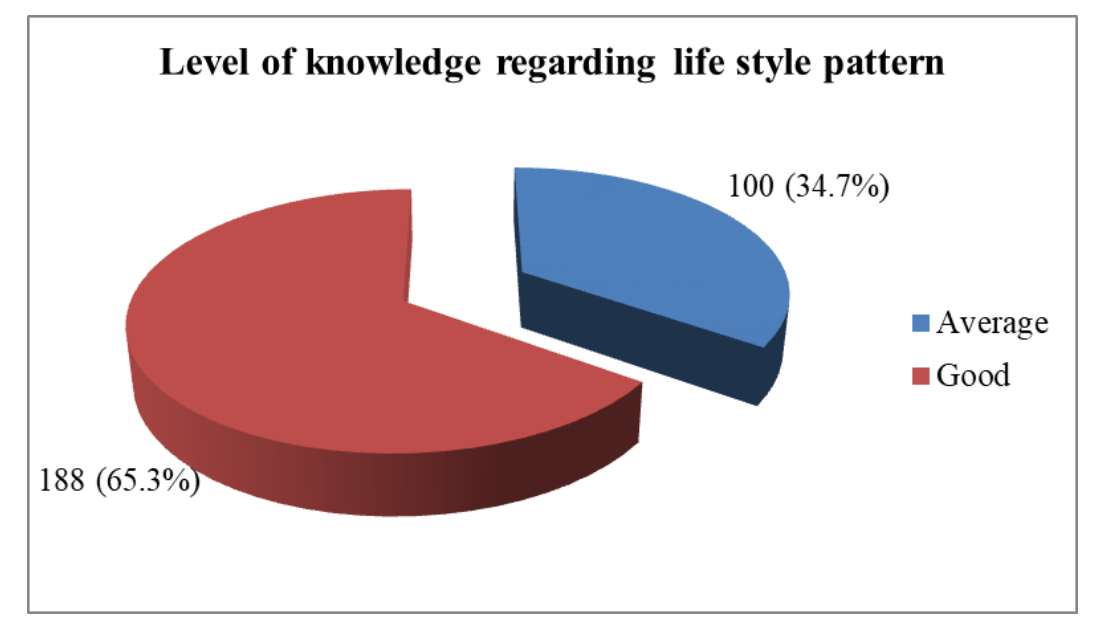

Figure 4 Distribution of respondents by level of knowledge regarding life style pattern $(n=288)$ 


\section{Discussion}

High blood pressure (BP) is one of the most important risk factors for cardiovascular disease (CVD). Most of the respondents knew that high blood pressure is a significant risk factor for heart disease

Diabetic patients have a two- to fourfold propensity to develop coronary artery disease (CAD) and myocardial infarction and type $2 \mathrm{DM}$ is an independent risk factor for stroke and heart disease. However, majority (76.7\%) of the rural community people had no knowledge regarding this issue. Other studies showed that majority of the respondents knew that diabetes mellitus is a risk factor for CVD [9]. The dissimilarity of results might be due to the difference in study place. The present study was entirely conducted in rural area while some studies covered both urban and rural communities, some covered only urban community. High cholesterol narrowed or blocked arteries which can lead to stroke, heart attack, or even heart failure. Though majority (56.3\%) of the rural community people had knowledge about it, a significant proportion of people (43.7\%) were unaware of it. Study conducted in Kuwait [4] also reported that majority (67.9\%) people had knowledge about it.

Stressful life events (e.g., death of a loved one, illness, trauma) have been associated with excess risk for cardiovascular disease (CVD) [10]. Stress was identified as risk factors by 53.0\% respondents which was consistent with other study [11]. Most of the respondents (92.0\%) had identified overweight as risk factors for cardiovascular disease (CVD) [4, 9].

The current study revealed that majority of the rural community people (73.3\%) had average knowledge on risk factors of cardiovascular disease while $14.9 \%$ had good knowledge. A systematic review aimed to synthesize available evidence of the level of knowledge of and perceptions towards CVDs and risk factors and found that Levels of knowledge and awareness for CVD and risk factors were generally low [12].

Only 25 (8.7\%) respondents had good knowledge while others had average $(n=190,66.0 \%)$ and poor $(n=73,25.3 \%)$ knowledge regarding sign and symptoms of cardiovascular disease. Another study determined the level of knowledge of signs and symptoms of heart attack and stroke in Singapore resident population and the level of knowledge for preselected, common signs and symptoms of heart attack and stroke was $57.8 \%$ and $57.1 \%$, respectively [13].

Majority of the study participants $(61.1 \%)$ had good knowledge while others had average $(n=105,36.5 \%)$ and poor $(\mathrm{n}=7,2.4 \%)$ knowledge regarding prevention of cardiovascular disease.

Most of the study participants (65.3\%) had good knowledge while others had average (n=100, 34.7\%) knowledge regarding life style pattern.

Service holders and businessmen have opportunity to communicate with many people from where they can get much information. On the other hand, house wives are confined at home and engaged themselves in house hold works. They get less opportunity to acquire knowledge.

\section{Conclusion}

People in the rural community have average knowledge regarding risk factors of cardio-vascular diseases and good knowledge regarding correct lifestyle pattern of cardiovascular diseases. This finding provide useful information for implementers of interventions targeted at the prevention and control of cardiovascular disease and encourages them to incorporate health promotion and awareness campaigns in order to enhance knowledge and awareness of cardiovascular diseases in the region.

\section{Compliance with ethical standards}

\section{Acknowledgments}

I am deeply indebted to my supervisor Prof. Dr. Md. Emdadul Haque, Head of the Department of Nutrition and Biochemistry, NIPSOM and express my best regards, hearty gratitude and sincere appreciation to his for his guidance, inspiration and close co-operation throughout the period of this study.

\section{Disclosure of conflict of interest}

None to declare. 


\section{Statement of informed consent}

Informed consent was obtained from all individual participants included in the study.

\section{References}

[1] Islam AKM M, Mohibullah AKM, Paul T. Cardiovascular Disease in Bangladesh: A review. Bangladesh Heart Journal. 2016; (31): 2.

[2] World Health Organization. Cardiovascular Diseases (CVDs). Fact Sheet N 317. January 2015.

[3] Amadi CE, Lawal FO, Mbakwem AC, Ajuluchukwu JN, Oke DA. Knowledge of cardiovascular disease risk factors and practice of primary prevention of cardiovascular disease by Community Pharmacists in Nigeria: a crosssectional study. International journal of clinical pharmacy. 2018; 40(6): 1587-1595.

[4] Awad A, Al-Nafisi H. Public knowledge of cardiovascular disease and its risk factors in Kuwait: a cross-sectional survey. BMC public health. 2014; 14(1): 1131.

[5] Islam AKM M, Mohibullah AKM, Paul T. Cardiovascular Disease in Bangladesh: A review. Bangladesh Heart Journal. 2016; (31): 2.

[6] Kromhout D, Menotti A, Kesteloot H, Sans S. Prevention of Coronary Heart Disease by Diet and Lifestyle. American Heart Association. 2002; 105: 893-898.

[7] Odegard AO, Koh WP, Gross MD, yuan JM, Pereira MA. Combined Lifestyle Factors and Cardiovascular Disease Mortality in Chinese Men and Women. American Heart Association. 2011; 124(25): 2847-54.

[8] Amarasekara P, Silva AD, Swarnamali H, Senarath U, Katulanda P. Knowledge, Attitudes and Practices on Lifestyle and Cardiovascular Risk Factors Among Metabolic Syndrome Patients in an Urban Tertiary Care Institute in Srilanka. Asia Pac J Public Health. 2016; 28(1): 32-40.

[9] Fahs I, Khalife Z, Malaeb D, Iskandarani M, Salameh P. The prevalence and awareness of cardiovascular diseases risk factors among the Lebanese population: a prospective study comparing urban to rural populations. Cardiology research and practice. 2017.

[10] Song H, et al. Stress related disorders and risk of cardiovascular disease: Population based, sibling controlled cohort study. BMJ. 2019; 365: 11255.

[11] Yuqiu L, Wright SCD. Knowledge and awareness of risk factors for cardiovascular disease in the Ga-Rankuwa community. Health SA Gesondheid. 2008; 13(3): 31-41.

[12] Boateng D, Wekesah F, Browne JL, Agyemang C, Agyei-Baffour P, Aikins ADG, Smit HA, Grobbee DE, KlipsteinGrobusch K. Knowledge and awareness of and perception towards cardiovascular disease risk in sub-Saharan Africa: A systematic review. PloS one. 2017; 12(12): p.e0189264.

[13] Quah JLJ, Yap S, Cheah SO, Ng YY, Goh ES, Doctor N, Leong BSH, Tiah L, Chia MYC, Ong MEH. Knowledge of signs and symptoms of heart attack and stroke among Singapore residents. BioMed research international. 2014. 